\title{
NeuroRegulation
}

\section{Editorial Perspective: Defining Neurofeedback and Its Functional Processes}

\author{
Rex L. Cannon ${ }^{1,2^{*}}$, Editor-in-Chief \\ ${ }^{1}$ Positive Brain Training, Lake Worth, Florida, USA \\ ${ }^{2}$ Neural Potential, Lake Worth, Florida, USA
}

\begin{abstract}
Neurofeedback is gaining widespread attention across clinical and research domains. As our knowledge of the brain and its enigmatic mechanisms increase, so does the interest in harnessing these mechanisms to promote improved mental processes and reduce symptomatic issues. Neuroscience advances and neurofeedback will continue to evolve into a primary focus for learning, performance, and reduction of symptoms in psychopathology. Likewise, electroencephalographic (EEG) and source localization techniques will improve our understanding and identification of biomarker EEG patterns to better identify and ultimately classify specific patterns associated with psychological and neurological syndromes. As technology and production of devices become more prevalent, there is a growing need to define the parameters used in neurofeedback, as well as to classify the processes into specific or nonspecific factors to avoid further confounds and problems across disciplines.
\end{abstract}

Keywords: neurofeedback; operant conditioning; operant learning; self-regulation; neuroplasticity; neural efficiency; neuromodulation

Citation: Cannon, R. L. (2015). Editorial Perspective: Defining Neurofeedback and Its Functional Processes. NeuroRegulation, 2(2), 60-69. http://dx.doi.org/10.15540/nr.2.2.60

*Address correspondence to: Rex L. Cannon, PhD, BCN, Chief Science Officer/Chief Operations Officer, Positive Brain Training and Neural Potential, 7170 Charleston Point Dr., Lake Worth, FL 33467, USA. Email: rexcannon@neuralpotential.com

Edited by:

Nancy L. Wigton, PhD, Grand Canyon University, Arizona, USA

Copyright: $\odot$ 2015. Cannon. This is an Open Access article distributed under the terms of the Creative Commons Attribution License (CC-BY).

Reviewed by:

John Davis, PhD, McMaster University, Ontario, Canada

Nancy L. Wigton, PhD, Grand Canyon University, Arizona, USA

\section{Introduction}

Over the course of the past 50 years, and more recently, neurofeedback has been gaining interest and popularity in the public eye and across disciplines devoted to human mental wellness and performance. The literature is replete with published reports describing the processes involved with neurofeedback and results of empirical studies using this procedure to treat psychological syndromes or functionality in normative groups. However, a clear operant definition for neurofeedback has been elusive. Thus, the term neurofeedback has been used widely in recent years in studies that target changes measured through techniques including electroencephalographic (EEG), current source density (CSD), functional magnetic resonance imaging (fMRI), magnetoencephalography (MEG), functional near-infrared spectroscopy (fNRIS) and others (Hammond, 2011; Thibault, Lifshitz, Birbaumer, \& Raz, 2015). Likewise, there have been countless devices developed for home use or entertainment that have adopted the term. However, accounts of the learning processes and biological mechanisms underlying neurofeedback are sparse. This is the impetus for this editorial perspective; as methods for operant learning through neurofeedback must be discussed, refined, and adopted into a rational format to further successful use of this method across research settings, peak performance, and mental health disciplines. This paper is not an attempt to validate neurofeedback as a method to treat psychiatric disorders; rather, it is a summary elucidating the mechanisms and procedures important to neurofeedback and learning in general.

\section{Neurofeedback}

Neurofeedback (EEG biofeedback, neurotherapy, neuroregulation) is a self-regulation technique that utilizes a brain computer interface $(\mathrm{BCl})$ to influence 
the processes of neural plasticity and neural efficiency. Neurofeedback is accomplished by providing the individual with feedback about the electrical activity of the brain within a specific frequency range at a specific target on the scalp. Neurofeedback has traditionally been accomplished by placing one or more sensors on the head to measure the EEG at a particular site, in a specific frequency range, so that auditory and/or visual stimuli are provided contingent on EEG activity reaching a target value. Through feedback human beings, animals, and even single neurons can learn to change and regulate EEG activity (or firing patterns thereof).

Neurofeedback is not to be confused with neurostimulation, transcranial magnetic stimulation, or any methodology that introduces a signal or pulse into the brain. These methods cannot be considered operant conditioning and therefore cannot be considered neurofeedback, because the stimuli involved are not contingent on any defined brain activity.

Neurofeedback may be defined as the presentation of a stimulus change contingent on brain activity that meets a target-specific defined criterion. At this time, three types of EEG neurofeedback can be described. Neurofeedback of the operant conditioning type $\left(\mathrm{NF}_{\mathrm{oc}}\right)$ requires EEG activity to reach a fixed criterion before feedback is delivered. In other cases the response threshold or criterion for feedback varies dynamically based on numerous moment-by-moment calculations of the antecedent EEG activity. Due to lack of specificity and details, such techniques are better classified as neurofeedback of an undifferentiated type (NF $\left.\mathrm{UT}_{\mathrm{UT}}\right)$. Finally, there are the commercially available devices that a user takes home and wears, to improve subjective experiences, typically without clear targets or known functional correlates (e.g., focus, relaxation, stress reduction). These methods can be classified as neurofeedback of the entertainment type $\left(\mathrm{NF}_{\mathrm{ET}}\right)$.

\section{Operant Conditioning}

Operant conditioning (OC) describes how we develop behaviors that operate upon the environment. OC was first investigated by Thorndike (1898) and later was expanded upon by Skinner (1938). In OC, a response that occurs with some minimum frequency is made to occur more frequently by following it with a particular type of reinforcement, be it positive or negative in form (Pear, 2001). As contrasted with respondent (i.e., classical) conditioning, OC involves directly associating a response with a stimulus event (not reward) rather than a stimulus with a stimulus. This is an important distinction that is often misguided and ill defined in learning research and clinical applications. A reward is a thing of value to an organism, whether it is food, water, points, monies, or any other stimulus. Reward is subject to individual differences except when a deprivation is present. Thus, the stimulus event's covariance with the desired response is the positive reinforcement (e.g., the car driving, ball bouncing, or beeping) and the reward directly follows the stimulus event. Behavior that has been learned through OC is called operant behavior, which may also be interpreted as learning to operate effectively and efficiently on the environment with its contingencies, consequences, and antecedent behaviors. A positive reinforcer is any stimulus whose presentation immediately following a response increases the probability of that response; while a negative reinforcer is any stimulus whose removal immediately following a response increases the probability of that response.

In laboratory experiments with animals it is well known that a deprivation must be present for the animal to engage in experimental protocols. For example, a socially enriched environment with a satiated (food, water, temperature, etc.) animal will be highly unlikely to engage in the process of pushing a lever for food, or other stimulus. Shaping of the response of interest is additionally important in the early stages of the experiment. Importantly and not always considered in the application of neurofeedback procedures, a deprivation must be present in order for shaping and conditioning of behavior to occur. Any human being presenting for neurofeedback training has an awareness of a deprivation (e.g., I can be better at memory, I would like to be less anxious, etc.). This is also true for individuals engaging in neurofeedback training for a particular syndrome. For example, children with Attention-deficit/Hyperactivity Disorder (ADHD) perceive there is a deficit in functionality as contrasted with other normative children, or interactions with teachers and parents. The same is true for the athlete or businessman wanting to perform at a higher level; or an individual with depression, anxiety, or any other problematic issues with emotional, cognitive, or adaptive skill sets. However, there are exceptions to every rule and in the case of $O C$ and awareness of a deprivation, it may not always be discernible due to disorders of communication (autism or traumatic brain injury) yet the EEG and its association with behavioral regulation (excessive movement, emotional 
reactivity, etc.) can be shaped and reinforced using OC.

Neurofeedback utilizes $O C$ in a specific context that focuses on the electrical activity of the brain at the scalp, current source density at a specific region of interest, or blood oxygenated level dependent (BOLD) activity at a specific region of interest. Additionally, an EEG frequency that occurs at some minimal rate (e.g., $2 \mathrm{uV}$ of beta to theta power, alpha power of $5 \mathrm{uV}$, or other designated anomaly) is targeted for conditioning. The most important measure in a neurofeedback learning paradigm is a learning curve that demonstrates acquisition has taken place; or more simply, that the individual has learned to change the EEG or brain activity in the desired direction. The formula for a neurofeedback mechanism using OC consists of a simple, yet elegant paradigm:

1. A value of a specific target frequency or set of target frequencies is selected (e.g., uV value of SMR, theta/beta ratio, or alpha amplitude).

2. A specific electrode site, set of sites, or region of training is selected (e.g., Cz, Fz, or anterior cingulate).

3. An establishing operation induces a motivational state based on the subject's deviation from a specified goal state (e.g., in ADHD, impairment of attention; in anxiety, the presence of an aversive subjective experience; in peak performance training, a greater than usual skill level).

4. Through positive or negative reinforcement, a desired change in EEG activity is documented.

5. Evidence of change is documented at other levels of analysis (e.g., subjective experience, psychopathology scales, neurophysiology assessments, cognitive or behavioral performance).
In many instances, research studies will document all of these elements. In a clinical setting this may be taxing on clinicians and technicians. However, it is not beyond the scope of a practitioner to produce a learning curve to provide evidence that acquisition has in fact occurred. I have conferred with several manufacturers of neurofeedback devices and all have affirmed the data within and across sessions is stored and accessible for production of learning curves; be it microvolt levels, percentage of time in reward, or points scored.

In the figures below, examples of group and individual acquisition curves are provided. Figure 1 shows an example of a learning curve for the average number of points generated for eight individuals with ADHD who had completed 17 to 20 sessions of neurofeedback. Figure 2 shows the average CSD for two study groups across sessions. Figure 3 shows the percentage of reward for an individual within and across 11 sessions. Figure 4 shows a learning trend for points scored in one session of neurofeedback for an individual.

There are two main requirements for demonstrating successful learning. The first is a stable trend in the desired direction. Although a linear trend is typical, nonlinear methods can also contribute to our understanding of learning across time (e.g., quadratic and cubic trends). For example, if one is training SMR uV levels up, then the plot of SMR should show an increasing positive trend. Likewise, if specific frequencies are inhibited, then the plot of voltage in those frequencies should demonstrate a decreasing trend. These can be considered the linear components of learning. Secondly, there should be a decrease in variance across sessions. For example, as the individual learns to self-regulate an EEG frequency, the values of EEG activity or number of points scored should become more consistent across sessions. The method of delivery (neurofeedback, MEG, fMRI, fNRIS) becomes secondary to the original definition of $O C$ and its functional units of measurement: If no acquisition is demonstrated in the variables being trained, then, despite any change in measures at other levels of analysis (e.g., self-report, behavior measures), the process cannot be classified as $\mathrm{NF}_{\text {oc }}$. 


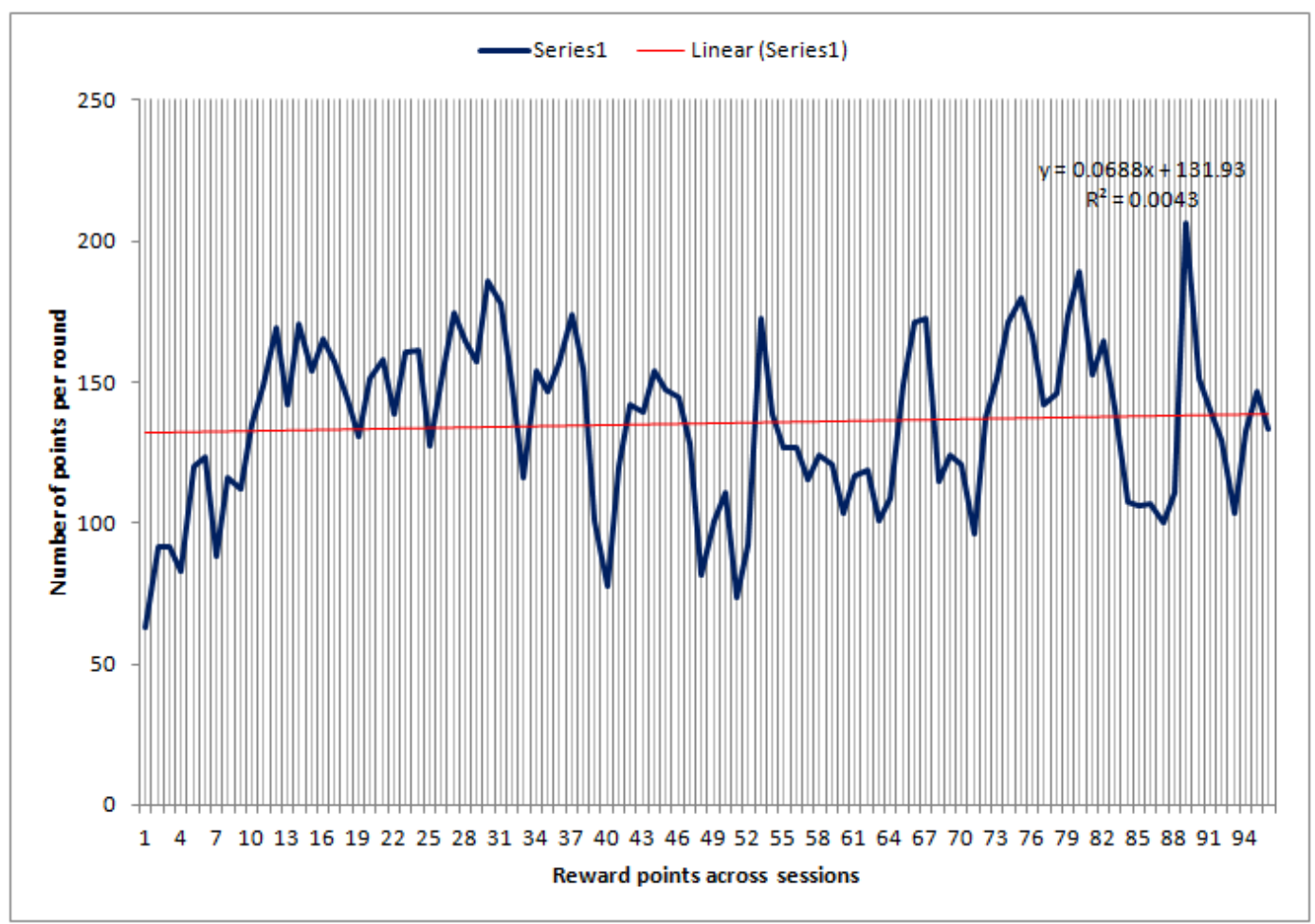

Figure 1. Average points scored across sessions for a group of 8 ADHD patients.

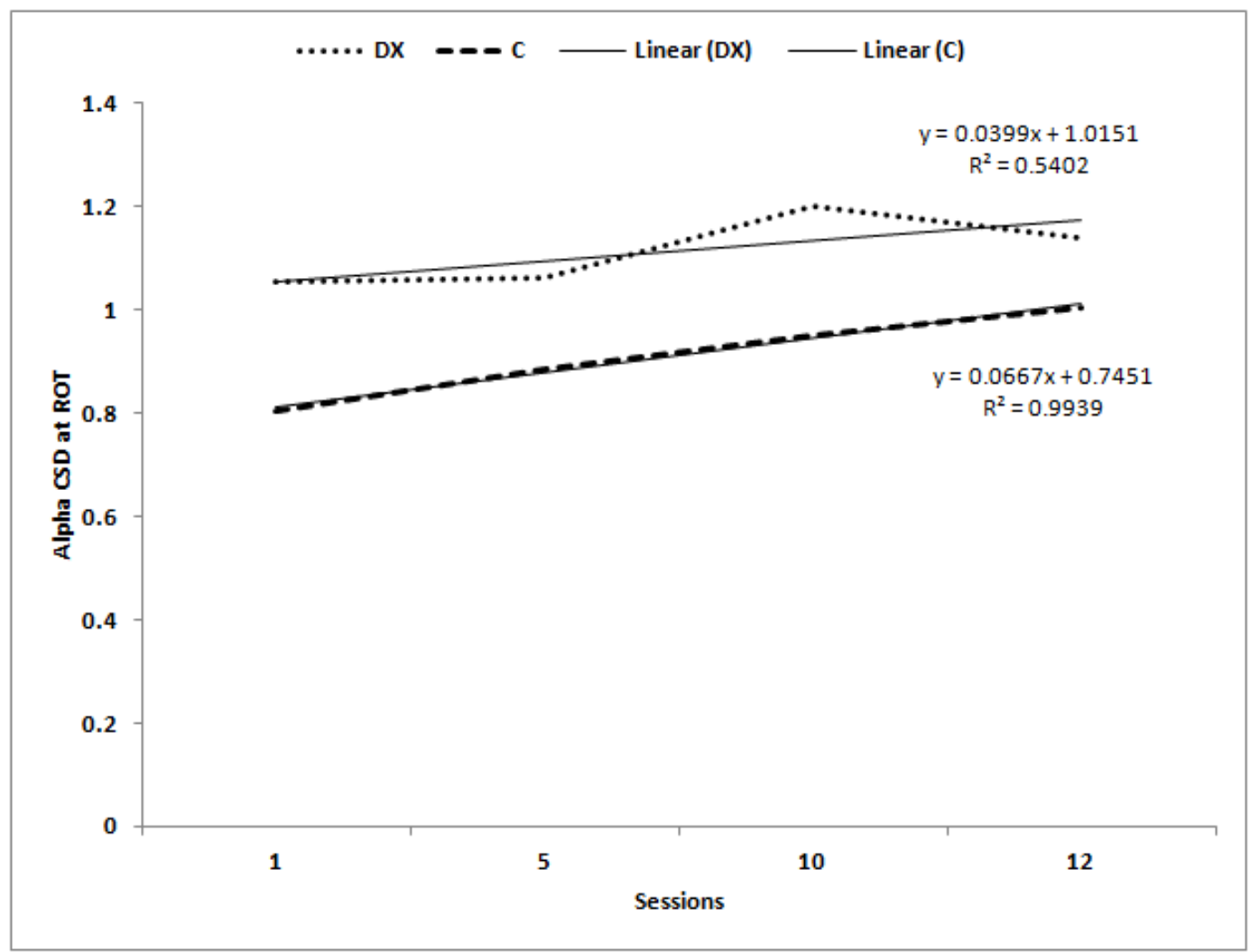

Figure 2. Two groups of individuals and average current source density (CSD) levels at the region of training (ROT) across sessions by using sessions 1, 5, 10 and 12 . 


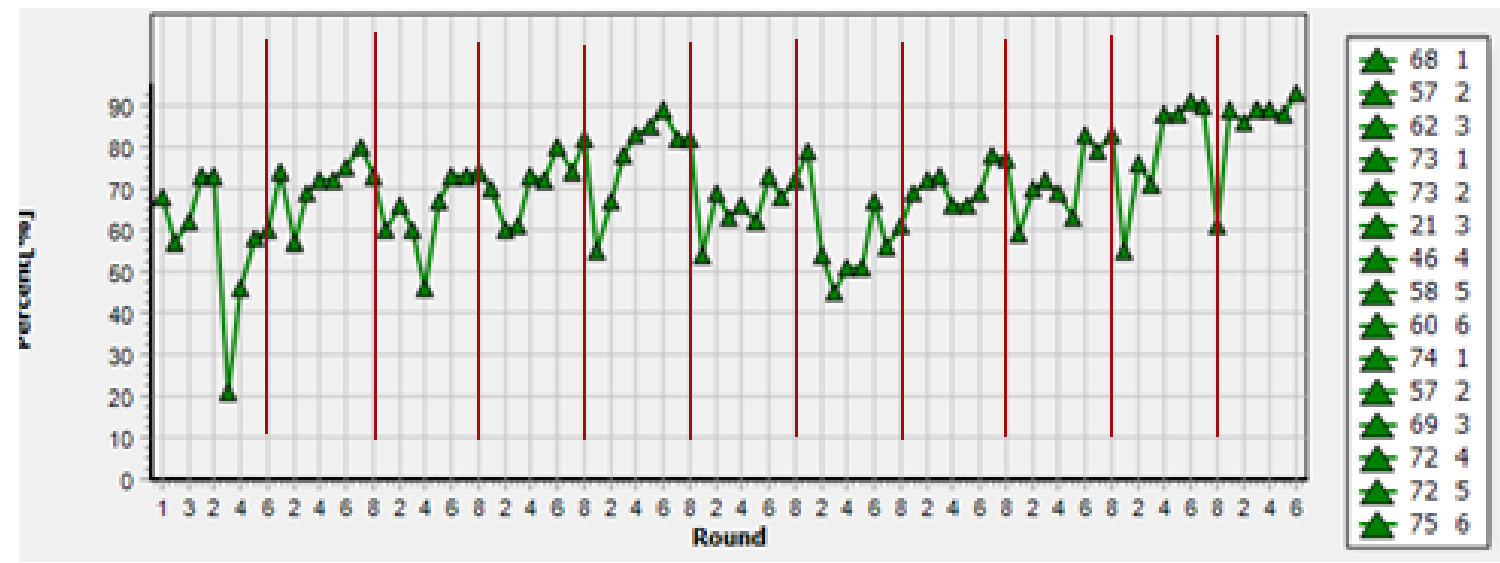

Figure 3. Percentage of time in reward for an individual across 11 sessions and within sessions. Each session consists of six 5-min training rounds.

\section{Total Score: 366}

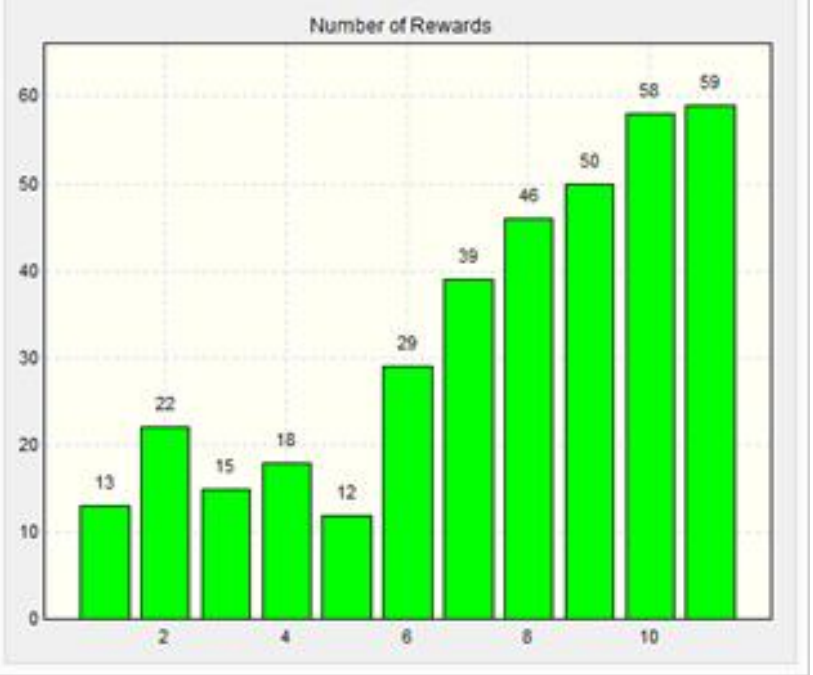

Figure 4. Learning trend generated by an individual within a single neurofeedback session. Number of rewards per 2 -min rounds; 11 rounds, for a total of 22 min training time.

\section{Neuroplasticity}

Neuroplasticity (NP) is the inherent capacity of the brain to develop new connections and pathways as a compensatory mechanism for injury, or as a function of learning in response to experience and changes in the environment. Practice and learning play a vital role in human brain plasticity over the lifespan (Kelly, Foxe, \& Garavan, 2006). Clearly, NP is the driving force in human learning (experiencedependent changes) over the lifespan. This experience-driven effect has refuted the long held position that the adult human brain is both hardwired and resistant to change (Holloway, Broadfield, \& Yuan, 2003). Experience-driven changes in the brain have been widely demonstrated in both human and nonhuman primates and these findings present exceptional challenges for observing these mechanisms in vivo. However, technology and human drive to understand have produced more advanced methods to capture how these mechanisms operate. This has contributed to the development of methodologies that influence these processes and to novel treatments and diagnostic techniques for disorders of learning. There is little doubt among neuroscientists that symptoms associated with most psychiatric disorders can be attributed to brain activity and functional network disruptions, regional activation patterns, and lack of the functional integration of systems required for operating effectively on the environment. Currently, the most promising measure of plastic changes in the human brain, as a function of learning and practice, are demonstrated by volumetric magnetic resonance imaging (VMRI). This method shows increases or decreases in white matter and grey matter volume as a function of learning or training (practice) including neurofeedback methods (Beauregard \& Lévesque, 2006; Ghaziri et al., 2013; Lévesque, Beauregard, \& Mensour, 2006; Petersson, Elfgren, \& Ingvar, 1999). Importantly, recent data have shown changes in individual neurons as an individual experiences new data (memories), as well as conditioning of spiking patterns in individual neurons in the hippocampus (Ishikawa, Matsumoto, Sakaguchi, Matsuki, \& Ikegaya, 2014; Ison, Quiroga, \& Fried, 2015). In most research demonstrating learning in human and nonhuman subjects, the principles of $\mathrm{OC}$ are followed and evidence of change is documented (Baxter \& Byrne, 2006; Cannon, Baldwin, et al., 
2014; Mozzachiodi, Lorenzetti, Baxter, \& Byrne, 2008; Spencer, Syed, \& Lukowiak, 1999; Sterman, 2000). Clearly this definition will evolve and adapt as technology and understanding improve. However, in as much as learning and self-regulation are involved, NP is the primary target for all behavioral treatments and processes (including education). As such, $\mathrm{NF}_{\mathrm{oc}}$ is a viable and reproducible method for improving NP associated with self-awareness, self-regulation, and behavior change.

\section{Neural Efficiency}

Neural efficiency (NE) and the effects of practice in the human brain offer the best promise in understanding behavior. Decreases in the extent or intensity of activations or activity are observed in the majority of studies examining task practice. The primary mechanism proposed to underlie activation decreases is increased NE; which, by definition, reflects an increased efficiency within a network such that operant efficiency now occurs with the engagement of fewer neural sources, as well as increased synchronous firing relative to a particular task or stimulus (Babiloni et al., 2009; Foerde et al., 2008; Poldrack, 2000, 2002; Poldrack, Desmond, Glover, \& Gabrieli, 1998; Poldrack \& Foerde, 2008; Poldrack \& Gabrieli, 2001; Poldrack \& Logan, 1997, 1998). Decreases in activation are suggested to reflect a more robust and efficient neural representation (Duncan \& Miller, 2002) or a more precise functional circuit related to a behavior or function of interest (Garavan, Kelley, Rosen, Rao, \& Stein, 2000). In several studies of practice effects in the brain, increases in activation or activity refer to two processes; practice-related expansions in the volume of cortical representations and increases in the strength or amplitude of activations (Kelly et al., 2006). Thus, NE is directly evident by a decrease in the number of resources (energy) allocated to perform a particular task. In many cases this may be referred to as automatic processing and can be thought of in terms of heartbeat, breathing, use of language, and those activities that are well learned and well practiced (the area or function of expertise). In EEG work, specifically we can think of NE in terms of EEG amplitude and global magnitude of the additive signals. For example, as an individual learns to regulate the behavior of sitting still and focusing on a stimulus we would expect an increase in the response of interest (e.g., SMR, low-beta, etc.). As the individual learns to generate this response and sustain it we would eventually expect a decrease in the signal amplitude once the skill is acquired. In sum, once an individual learns and masters a task we can surmise that the brain has adapted to best perform this task with minimal resource depletion.

\section{Self-regulation}

Self-regulation (SR) is a highly adaptive and powerful process (Vohs, Baumeister, \& Ciarocco, 2005; Vohs et al., 2008). SR refers to the self's capacity to alter its behaviors based in the degree that human beings are adaptive and flexible (Vohs et al., 2005). Alternatively, SR can better be defined as plasticity that relies upon the functional integrity and NE of the brain and its network convergence or divergence in executive processes; including, selfmonitoring, self-concept, self-control, selfperception, self-organization, self-related goal setting, planning, and agency (Cannon, Congedo, Lubar, \& Hutchens, 2009; Cannon et al., 2007; Cannon \& Baldwin, 2012; de Greck et al., 2008; Northoff et al., 2006). This is reinforced by evidence of clinical applications of SR in which Baumeister, Gailliot, DeWall, and Oaten (2006) and de Ridder and de Wit (2006) have proposed that whatever differences and deficits exist in the ability to selfregulate, either innate or learned during development, can be modified by additional learning. Thus, SR is the neural process of data integration and learning as it pertains to the self and its experiential functionality; or more simply, an adaptive data-driven process (Cannon, 2012).

SR is a skill necessary for reliable emotional wellbeing, or affective constancy. It is proposed that differential variants of SR include emotional, behavioral, and cognitive variants. Importantly, the most overlooked construct necessary for SR is language (defined as the ability to communicate, including internal self-directed speech) and practice. If, like many authors suggest, self-regulation is a skill or set of skills, then mastery of this skill requires extensive practice and learning. The key components for practice in the human brain are NP and NE. These components have been demonstrated in numerous fMRI studies of practice (Frackowiak \& Ward, 2004; Fraser et al., 2002; Garrido et al., 2009; Kelly et al., 2006; Neville \& Bavelier, 2002). It is well known that practice in effect can induce activation (learning) and decreased activation (well-learnt and less energy required) in numerous experimental conditions, from stringed instruments (Elbert, Pantev, Wienbruch, Rockstroh, \& Taub, 1995), to motor functions (Fraser et al., 2002), verbal recall (Andreasen et al., 1995), and working memory (von Bastian, Langer, Jäncke, \& Oberauer, 2013). Thus, there is sufficient 
evidence that practice (learning by repetition) influences neural networks in both positive and negative fashion. Probably the best example of a negative instance is depression or anxiety. We might consider the influence of negative self-directed speech (Cannon, Lubar, Sokhadze, \& Baldwin, 2008; Gilbert, Dumontheil, Simons, Frith, \& Burgess, 2007) or processing of derogatory (Baumeister, 2003) appraisals of self by the self or others (Kim et al., 2008) and its potential effects in networks associated with the physiological response to stress. With the large literature of practice and learning and the role of SR across the biobehavioral spectrum we might strongly consider SR as the primary mechanism of action in neurotherapeutic procedures that require operant conditioning or learning (e.g., EEG biofeedback, neurofeedback; Kamiya, 2011; Wood \& Peut, 1981).

Experience-dependent changes in the human brain can occur from a synaptic to a cortical level throughout the life span. There is a growing literature base demonstrating these NP effects in both human and nonhuman populations. NP can be thought of in terms of development, such that in our earliest periods of development we assimilate information because of learning (operant behavior) by mimicking, observing, and experiencing the environment. We also begin to organize our self critically based on our perceptions of self in relation to others (operant behavior driven by self-perception and its relation to the environment). As development progresses, so does the datadependency requirements on the brain through which we learn to adapt an operant efficiency (the result of learning, practice, and specialization) relative to our culture, profession, ethnicity, and so forth. In essence, development is a function of operant learning, and disorders of learning begin and end with the central nervous system and its functional integrity (Cannon, Baldwin, et al., 2014).

Executive functions and self-regulation are better considered as synonymous, rather than independent processes and may best be described with functional neural signatures (e.g., functional integrity of the CNS) within the context of the Papez circuit (1937). One very important research finding-that is often overlooked or unknown in research paradigms investigating the limbic system and its function-is that hippocampal firing (generation of the theta frequency) is directly dependent on septal firing; that is to say, the hippocampus does not function independent of the septal area. Thus, the whole of the Papez circuit is proposed to be a specific network of mechanisms to integrate sensory, internal dialogue, and external information to regulate the hypothalamus and its control over behavioral patterns (Parmeggiani, Azzaroni, \& Lenzi, 1971).

It is when some aspect of data integration is compromised and specific neural data-dependency modules become overly practiced and efficient within a maladaptive context (e.g., negative selfperception, abuse, poor affect regulation, or external and internal stressors) relative to the self occurs, that problems in operant efficiency and psychological well-being are compromised. Neurofeedback, in all its forms, holds great potential in providing an evidence-based mechanism for improving emotional and regulatory processes (Johnston, Boehm, Healy, Goebel, \& Linden, 2010; Johnston et al., 2011). It is reasonable to consider that the self (organized neural networks) is both malleable and in some aspects more resistant to the effects of new learning (i.e., religion, disciplines, values, morality). It may also be that there are specific genetic mechanisms associated with the homeostatic maintenance of the organism that become disorganized or skewed toward a negative data-selection process. As put forth by Cannon, Baldwin, et al. (2014), SR can be conceptualized within this framework: Behavioral Equilibrium (BE; or Operant Efficiency) is dependent (on the output) of the interaction between emotional equilibrium $(\mathrm{EE})$ and homeostasis $(\mathrm{HS})$; or $\mathrm{BE}=\mathrm{EE} / \mathrm{HS}$. The mediating variable for Operant Efficiency or Operant Inefficiency is SR or its equivalent executive functions. The primary assumptions underlying this model are NP and NE.

In sum, SR is directly related to NP and NE, and the role of these two processes in theory is based on cognitive and verbal tasks that show specific activations or deactivations as an effect of practice and learning, treatment effects of neurofeedback, transcranial magnetic stimulation, cognitive behavioral therapy, and/or other treatment models that have shown pre-post changes in the cortical landscape. Thus, the fundamental processes (mechanisms of action) underlying all NFoc techniques, regardless of methodology, are NP and NE directed toward improved SR and learning (Johnston et al., 2010; Johnston et al., 2011) for optimal Operant Efficiency. 


\section{Conclusions}

Neurofeedback continues to gain widespread interest and attention from numerous research, clinical, and performance-related disciplines. It therefore becomes pertinent to define the processes associated with neurofeedback and to differentiate between these methods. A large number of data have shown positive results for neurofeedback across methods. However, not all neurofeedback can be said to involve OC (Cannon, Pigott, et al., 2014). Operant conditioning requires a complete set of fundamental components, some of which are often lacking in both research and clinical realms. Thus, we might consider a classification system for neurofeedback with three designations: $\mathrm{NF}_{\mathrm{OC}}, \mathrm{NF}_{\mathrm{UT}}$, and $\mathrm{NF}_{\mathrm{ET}}$. Differentiating neurofeedback methods in these terms may resolve contradictory findings, could aid in reducing the number of confounds in research studies, and provide clients clear information on which to base their consent to treatment. Neurofeedback offers promise for influencing learning and SR across a variety of normative and clinical groups. Its methods and their description must improve along with technological advancements so that better and more consistent outcomes can be achieved.

\section{Author Note:}

Author reports no conflicts of interest.

\section{References}

Andreasen, N. C., O'Leary, D. S., Cizadlo, T., Arndt, S., Rezai, K., Watkins, G. L., ... Hichwa, R. D. (1995). PET studies of memory: Novel versus practiced free recall of word lists. Neurolmage, 2(4), 296-305. http://dx.doi.org/10.1006/nimg.1995.1037

Babiloni, C., Marzano, N., Infarinato, F., lacoboni, M., Rizza, G., Aschieri, P., ... Del Percio, C. (2009). "Neural efficiency" of experts' brain during judgment of actions: A high-resolution EEG study in elite and amateur karate athletes. Behavioural Brain Research, 207(2), 466--475.

http://dx.doi.org/10.1016/j.bbr.2009.10.034

Baumeister, R. F. (2003). Ego depletion and self-regulation failure: A resource model of self-control. Alcoholism: Clinical \& Experimental Research, 27(2), 281-284. http://dx.doi.org/10.1097/01.ALC.0000060879.61384.A4

Baumeister, R. F., Gailliot, M., DeWall, C. N., \& Oaten, M. (2006). Self-regulation and personality: How interventions increase regulatory success, and how depletion moderates the effects of traits on behavior. Journal of Personality, 74(6), 17731802. http://dx.doi.org/10.1111/j.1467-6494.2006.00428.x

Baxter, D. A., \& Byrne, J. H. (2006). Feeding behavior of Aplysia: A model system for comparing cellular mechanisms of classical and operant conditioning. Learning and Memory, 13(6), 669-680. http://dx.doi.org/10.1101//m.339206

Beauregard, M., \& Lévesque, J. (2006). Functional magnetic resonance imaging investigation of the effects of neurofeedback training on the neural bases of selective attention and response inhibition in children with attentiondeficit/hyperactivity disorder. Applied Psychophysiology and
Biofeedback, 31(1), 3-20. http://dx.doi.org/10.1007/s10484006-9001-y

Cannon, R., Congedo, M., Lubar, J., \& Hutchens, T. (2009). Differentiating a network of executive attention: LORETA neurofeedback in anterior cingulate and dorsolateral prefrontal cortices. International Journal of Neuroscience, 119(3), 404-441.

http://dx.doi.org/10.1080/00207450802480325

Cannon, R., Lubar, J., Congedo, M., Thornton, K., Towler, K., \& Hutchens, T. (2007). The effects of neurofeedback training in the cognitive division of the anterior cingulate gyrus. International Journal of Neuroscience, 117(3), 337-357. http://dx.doi.org/10.1080/00207450500514003

Cannon, R. L. (2012). Low resolution electromagnetic brain tomography (LORETA): Basic concepts and clinical applications. Corpus Christi, TX: BMED Press.

Cannon, R. L., \& Baldwin, D. R. (2012). EEG current source density and the phenomenology of the default network. Clinical EEG and Neuroscience, 43(4), 257-267. http://dx.doi.org/10.1177/1550059412449780

Cannon, R. L., Baldwin, D. R., Diloreto, D. J., Phillips, S. T., Shaw, T. L., \& Levy, J. J. (2014). LORETA neurofeedback in the precuneus: Operant conditioning in basic mechanisms of self-regulation. Clinical EEG and Neuroscience, 45(4), 238248. http://dx.doi.org/10.1177/1550059413512796

Cannon, R. L., Lubar, J. F., Sokhadze, E., \& Baldwin, D. R. (2008). LORETA Neurofeedback for Addiction and the possible neurophysiology of psychological processes influenced: A case study and region of interest analysis of LORETA neurofeedback in right anterior cingulate cortex. Journal of Neurotherapy, 12(4), 227-241. http://dx.doi.org/10.1080/10874200802501948

Cannon, R. L., Pigott, H. E., Surmeli, T., Simkin, D. R., Thatcher, R. W., Van den Bergh, W., ... Koberda, J. L. (2014). The problem of patient heterogeneity and lack of proper training in a study of EEG neurofeedback in children. Journal of Clinical Psychiatry, 75(3), 289-290. http://dx.doi.org/10.4088/JCP.13lr08850

de Greck, M., Rotte, M., Paus, R., Moritz, D., Thiemann, R., Proesch, U., ... Northoff, G. (2008). Is our self based on reward? Self-relatedness recruits neural activity in the reward system. Neurolmage, 39(4), 2066-2075. http://dx.doi.org/10.1016/j.neuroimage.2007.11.006

de Ridder, T. D., \& de Wit, J. B. F. (Eds.). (2006). Self-regulation in Health Behavior. West Sussex: John Wiley \& Sons Ltd.

Duncan, J., \& Miller, E. K. (2002). Cognitive focusing through adaptive neural coding in the primate prefrontal cortex. In D. Stuss, \& R. T. Knight (Eds.), Principles of Frontal Lobe Function (pp. 278-291). Oxford: Oxford University Press.

Elbert, T., Pantev, C., Wienbruch, C., Rockstroh, B., \& Taub, E. (1995). Increased cortical representation of the fingers of the left hand in string players. Science, 270(5234), 305-307. http://dx.doi.org/10.1126/science.270.5234.305

Foerde, K., Poldrack, R. A., Knowlton, B. J., Sabb, F. W., Bookheimer, S. Y., Bilder, R. M., ... Asarnow, R. F. (2008). Selective corticostriatal dysfunction in schizophrenia: Examination of motor and cognitive skill learning. Neuropsychology, 22(1), 100-109. http://dx.doi.org/10.1037/0894-4105.22.1.100

Frackowiak, R. S., \& Ward, N. S. (2004). Recovery of function and plasticity in human brain. Royal Academy of Medicine in Belgium, 159(Pt 2), 145-155.

Fraser, C., Power, M., Hamdy, S., Rothwell, J., Hobday, D., Hollander, I., ... Thompson, D. (2002). Driving plasticity in human adult motor cortex is associated with improved motor function after brain injury. Neuron, 34(5), 831-840. http://dx.doi.org/10.1016/S0896-6273(02)00705-5

Garavan, H., Kelley, D., Rosen, A., Rao, S. M., \& Stein, E. A. (2000). Practice-related functional activation changes in a 
working memory task. Microscopy Research Technique, 51(1), 54-63.

http://dx.doi.org/10.1002/1097-0029(20001001)51:1<54::AIDJEMT6>3.0.CO;2-J

Garrido, M. I., Kilner, J. M., Kiebel, S. J., Stephan, K. E., Baldeweg, T., \& Friston, K. J. (2009). Repetition suppression and plasticity in the human brain. Neurolmage, 48(1), 269279. http://dx.doi.org/10.1016/j.neuroimage.2009.06.034

Ghaziri, J., Tucholka, A., Larue, V., Blanchette-Sylvestre, M., Reyburn, G., Gilbert, G., ... Beauregard, M. (2013). Neurofeedback training induces changes in white and gray matter. Clinical EEG and Neuroscience, 44(4), 265-272. http://dx.doi.org/10.1177/1550059413476031

Gilbert, S. J., Dumontheil, I., Simons, J. S., Frith, C. D., \& Burgess, P. W. (2007). Comment on "Wandering minds: the default network and stimulus-independent thought." Science, 317(5834), 43. http://dx.doi.org/10.1126/science.1140801

Hammond, D. C. (2011). What is neurofeedback: An update. Journal of Neurotherapy, 15(4), 305-336. http://dx.doi.org/10.1080/10874208.2011.623090

Holloway, R. L., Broadfield, D. C., \& Yuan, M. S. (2003). Morphology and histology of chimpanzee primary visual striate cortex indicate that brain reorganization predated brain expansion in early hominid evolution. The Anatomical Record, 273A(1), 594-602. http://dx.doi.org/10.1002/ar.a.10071

Ishikawa, D., Matsumoto, N., Sakaguchi, T., Matsuki, N., \& Ikegaya, Y. (2014). Operant conditioning of synaptic and spiking activity patterns in single hippocampal neurons. The Journal of Neuroscience, 34(14), 5044-5053. http://dx.doi.org/10.1523/JNEUROSCI.5298-13.2014

Ison, M. J., Quiroga, R. Q., \& Fried, I. (2015). Rapid encoding of new memories by individual neurons in the human brain. Neuron, 87(1), 220-230. http://dx.doi.org/10.1016/j.neuron.2015.06.016

Johnston, S. J., Boehm, S. G., Healy, D., Goebel, R., \& Linden, D. E. J. (2010). Neurofeedback: A promising tool for the selfregulation of emotion networks. Neurolmage, 49(1), 10661072. http://dx.doi.org/10.1016/j.neuroimage.2009.07.056

Johnston, S., Linden, D. E. J., Healy, D., Goebel, R., Habes, I., \& Boehm, S. G. (2011). Upregulation of emotion areas through neurofeedback with a focus on positive mood. Cognitive, Affective, \& Behavioral Neuroscience, 11(1), 44-51. http://dx.doi.org/10.3758/s13415-010-0010-1

Kamiya, J. (2011). The first communications about operant conditioning of the EEG. Journal of Neurotherapy, 15(1), 6573. http://dx.doi.org/10.1080/10874208.2011.545764

Kelly, C., Foxe, J. J., \& Garavan, H. (2006). Patterns of normal human brain plasticity after practice and their implications for neurorehabilitation. Archives of Physical Medicine and Rehabilitation, 87(12 Suppl 2), S20-29. http://dx.doi.org/10.1016/j.apmr.2006.08.333

Kim, J.-W., Choi, E. A., Kim, J.-J., Jeong, B. S., Kim, S.-E., \& Ki, S. W. (2008). The role of amygdala during auditory verbal imagery of derogatory appraisals by others. Neuroscience Letters, 446(1), 1-6. http://dx.doi.org/10.1016/j.neulet.2008.09.019

Lévesque, J., Beauregard, M., \& Mensour, B. (2006). Effect of neurofeedback training on the neural substrates of selective attention in children with attention-deficit/hyperactivity disorder: A functional magnetic resonance imaging study. Neuroscience Letters, 394(3), 216-221. http://dx.doi.org/10.1016/j.neulet.2005.10.100

Mozzachiodi, R., Lorenzetti, F. D., Baxter, D. A., \& Byrne, J. H. (2008). Changes in neuronal excitability serve as a mechanism of long-term memory for operant conditioning. Nature Neuroscience, 11(10), 1146-1148. http://dx.doi.org/10.1038/nn.2184

Neville, H., \& Bavelier, D. (2002). Human brain plasticity: Evidence from sensory deprivation and altered language experience. Progress in Brain Research, 138, 177-188. http://dx.doi.org/10.1016/S0079-6123(02)38078-6

Northoff, G., Heinzel, A., de Greck, M., Bermpohl, F., Dobrowolny, H., \& Panksepp, J. (2006). Self-referential processing in our brain-A meta-analysis of imaging studies on the self. Neurolmage, 31(1), 440-457. http://dx.doi.org/10.1016/j.neuroimage.2005.12.002

Parmeggiani, P. L., Azzaroni, A., \& Lenzi, P. (1971). On the functional significance of the circuit of Papez. Brain Research, 30(2), 357-374. http://dx.doi.org/10.1016/0006-8993(71)90086-2

Pear, J. (2001). The science of learning. Psychology Press.

Petersson, K. M., Elfgren, C., \& Ingvar, M. (1999). Dynamic changes in the functional anatomy of the human brain during recall of abstract designs related to practice. Neuropsychologia, 37(5), 567-587.

Poldrack, R. A. (2000). Imaging brain plasticity: Conceptual and methodological issues-A theoretical review. Neurolmage, 12(1), 1-13. http://dx.doi.org/10.1006/nimg.2000.0596

Poldrack, R. A. (2002). Neural systems for perceptual skill learning. Behavioral and Cognitive Neuroscience Reviews, 1(1), 76-83. http://dx.doi.org/10.1177/1534582302001001005

Poldrack, R. A., Desmond, J. E., Glover, G. H., \& Gabrieli, J. D. (1998). The neural basis of visual skill learning: An fMRI study of mirror reading. Cerebral Cortex, 8(1), 1-10. http://dx.doi.org/10.1093/cercor/8.1.1

Poldrack, R. A., \& Foerde, K. (2008). Category learning and the memory systems debate. Neuroscience and Biobehavioral Reviews, 32(2), 197-205. http://dx.doi.org/10.1016/j.neubiorev.2007.07.007

Poldrack, R. A., \& Gabrieli, J. D. E. (2001). Characterizing the neural mechanisms of skill learning and repetition priming: Evidence from mirror reading. Brain, 124(1), 67-82. http://dx.doi.org/10.1093/brain/124.1.67

Poldrack, R. A., \& Logan, G. D. (1997). Fluency and response speed in recognition judgments. Memory and Cognition, 25(1), 1-10. http://dx.doi.org/10.3758/BF03197280

Poldrack, R. A., \& Logan, G. D. (1998). What is the mechanism for fluency in successive recognition? Acta Psychologica, 98(2-3), 167-181. http://dx.doi.org/10.1016/S0001-6918(97)00041-3

Skinner, B. F. (1938). The Behavior of Organisms: An Experimental Analysis. New York: Appleton-Century.

Spencer, G. E., Syed, N. I., \& Lukowiak, K. (1999). Neural changes after operant conditioning of the aerial respiratory behavior in Lymnaea stagnalis. The Journal of Neuroscience, 19(5), 1836-1843.

Sterman, M. B. (2000). Basic concepts and clinical findings in the treatment of seizure disorders with EEG operant conditioning. Clinical EEG and Neuroscience, 31(1), 45-55. http://dx.doi.org/10.1177/155005940003100111

Thibault, R. T., Lifshitz, M., Birbaumer, N., \& Raz, A. (2015). Neurofeedback, self-regulation, and brain imaging: Clinical science and fad in the service of mental disorders. Psychotherapy and Psychosomatics, 84(4), 193-207. http://dx.doi.org/10.1159/000371714

Thorndike, E. L. (1898). Animal Intelligence: An experimental study of the associative process in animals. Psychological Monographs: General and Applied, 2(4), i-109.

Vohs, K. D., Baumeister, R. F., \& Ciarocco, N. J. (2005). Selfregulation and self-presentation: Regulatory resource depletion impairs impression management and effortful selfpresentation depletes regulatory resources. Journal of Personality and Social Psychology, 88(4), 632-657. http://dx.doi.org/10.1037/0022-3514.88.4.632

Vohs, K. D., Baumeister, R. F., Schmeichel, B. J., Twenge, J. M., Nelson, N. M., \& Tice, D. M. (2008). Making choices impairs subsequent self-control: A limited-resource account of decision making, self-regulation, and active initiative. Journal 
of Personality and Social Psychology, 94(5), 883-898. http://dx.doi.org/10.1037/0022-3514.94.5.883

von Bastian, C. C., Langer, N., Jäncke, L., \& Oberauer, K. (2013).

Effects of working memory training in young and old adults. Memory \& Cognition, 41(4), 611-624. http://dx.doi.org/10.3758/s13421-012-0280-7

Wood, D. J., \& Pesut, D. J. (1981). Self-regulatory mental processes and patient recovery. Western Journal of Nursing Research, 3(3), 262-267.

http://dx.doi.org/10.1177/019394598100300322

Received: July 5, 2015

Accepted: July 10, 2015

Published: July 15, 2015 